\title{
Physical Ability and Comorbidity and Oral Health Among Home-Dwelling Older People in the Finnish Population
}

Antti Tiisanoja ${ }^{1,2}$, Matti Kuukasjärvi ${ }^{1}$, Anna-Maija Syrjälä ${ }^{1,2}$, Kaija Komulainen $^{3}$, Matti Knuuttila ${ }^{1}$, Sirpa Hartikainen ${ }^{4}$, Pekka Ylöstalo ${ }^{1,2}$

${ }^{1}$ Periodontology and Geriatric Dentistry, Research Unit of Oral Health Sciences, University of Oulu, Oulu

${ }^{2}$ Medical Research Center Oulu, Oulu University Hospital and University of Oulu, Oulu ${ }^{3}$ Institute of Dentistry, University of Eastern Finland, Kuopio

${ }^{4}$ Kuopio Research Centre for Geriatric Care, School of Pharmacy, University of Eastern Finland, Kuopio

1, 2, 3, 4 Finland

Running title: Physical Ability and Oral health

Number of tables: 3 ; number of figures: 0

Corresponding author:

Antti Tiisanoja

Research Unit of Oral Health Sciences

P.O. BOX 5281

FI-90401, University of Oulu

Finland

antti.tiisanoja@oulu.fi 


\section{Abstract}

Aim: To examine how physical ability and comorbidity associate with oral health.

Methods and results: The study population comprised of 161 individuals belonging to the Oral Health GeMS study. Outcome variables were the number of teeth with dental caries and deepened periodontal pockets, and self-perceived oral health (pain/discomfort in mouth). Physical ability was determined by measuring limitations in daily activities (Activities of Daily Living, ADL and Instrumental Activities of Daily Life, IADL) and the number of comorbidities with Functional Comorbidity Index (FCl). Poisson's multivariate regression model was used to estimate prevalence rate ratio (PRR) and their 95\% confidence intervals $(\mathrm{Cl})$. The physical ability or number of comorbidities did not associate consistently with oral diseases, but ADL, IADL, and FCI associated all with self-perceived oral discomfort (PRR: 1.74, Cl: 1.00-3.03; PRR: 1.20, Cl: 1.06-1.35; PRR: 1.20, Cl: 1.051.36, respectively). Furthermore, IADL associated also with poor self-perceived oral health (PRR: 1.27, Cl: 1.03-1.57).

Conclusion: Older people with impaired physical ability and comorbidities are more likely to have oral discomfort and have poorer self-perceived oral health.

Keywords: physical ability, comorbidity, oral health 


\section{Introduction}

The number of older people is rising around the world. In general, the proportion of people aged $\geq 60$ years is predicted to almost double by 2050 and what is also noteworthy is that-especially in developed countries—-the number of "oldest-old" (people aged $\geq 80$ years) will increase even faster than the older population as a whole (almost triple by 2050) $)^{1}$ As the population ages, this predisposes challenges to the health care systems worldwide, including also to dental care providers. For example, in multiple countriesUSA $^{2}$, Denmark 3 , Finland ${ }^{4}$ — the number of dentate older people ( $\geq 65$ years) has increased steadily in the last decades and this trend has simultaneously increased the age group's need for dental treatment.

It is known that aging and multiple morbidities deteriorate person's physical and functional ability and it follows that a growing number of community-dwelling older people require help in daily life ${ }^{5}$. Activities of Daily Life (ADL) ${ }^{6}$ and Instrumental Activities of Daily Life $(\mathrm{IADL})^{7}$ are validated tools that assess physical and functional ability, whereas Functional Comorbidity Index ${ }^{8}(\mathrm{FCl})$ is a validated tool for measuring comorbidities. When used together, these tools provide a comprehensive manner to assess coping in daily life.

The deterioration in daily activities has been shown to associate with poor oral health ${ }^{9-12}$. However, the role of physical ability in the aetiology of oral diseases is still unclear as there are findings for ${ }^{9-12}$ and against ${ }^{13,14}$. Furthermore, the results related to physical ability and self-perceived oral health are also inconclusive with findings for ${ }^{15-19}$ and against ${ }^{20}$.

This paper aimed to study comprehensively how physical ability, measured with ADL and IADL, and comorbidity, measured with $\mathrm{FCl}$, associate with dental caries, periodontal disease, and self-perceived oral health in a group of community-living older people. 


\section{Material and methods}

The study followed the STROBE (Strengthening the Reporting of Observational Studies in Epidemiology) guidelines.

\section{Study population}

The current study is a secondary analysis of the cross-sectional data from the Oral Health GeMS study (Geriatric Multidisciplinary Strategy for the Good Care of the Elderly), which was a part of the larger population-based parent GeMS study. The parent GeMS consisted of randomly selected citizens at least 75 years of age on the 1st of November 2003 and living in Kuopio, Finland $(n=1000)$, who were divided into geriatric intervention $(n=500)$ and control $(n=500)$ groups. The Oral Health group consisted of the parent geriatric intervention group and an oral clinical examination was performed for 354 out of 500 people in the group (104 refused, 40 died, and 2 moved). After restriction to non-smoking, dentate (at least one clinically visible tooth or root in either of the jaws) and home-dwelling participants, the study population consisted of 161 individuals.

The participants or their relatives provided written informed consent. The study protocols of the original GeMS and Oral Health GeMS studies were approved by the ethics committee of the Hospital District of Northern Savo. Approval for the current study was received accordingly from the University of Eastern Finland (former University of Kuopio). More detailed information about the parent GeMS study and the Oral Health GeMS study is available in previously published papers ${ }^{21,22}$.

\section{Comprehensive geriatric assessment}

A multidisciplinary team of nurses, physiotherapists and physicians specialising in geriatrics conducted a comprehensive geriatric assessment of all the participants. The participants were interviewed about their health behaviour and clinically examined, mainly 
in local municipal health centres. The examinations and the interviews were also performed in a home environment if the person was not able to arrive at the health centre or preferred a home visit. If a participant was unable to answer the questions because of medical reasons, the information was provided by relatives or caregivers. Information from medical records was also used in the study.

\section{Clinical oral examination}

The oral health interviews and the clinical oral examinations were performed by two experienced dentists in 2004-2005. The examinations took place at the social and health care centre of Kuopio, or if the participants preferred home visits, at their homes. The clinical oral examination procedures were standardised by dentists examining seven participants together and during the study, workshops were held to resolve any problems that arose. The oral examination was performed in a dental unit following a pre-written protocol. Repeated or parallel clinical oral examinations were not conducted due to the high age of the participants and the lengthy examination time.

\section{Outcome variables}

The outcome variables of this study were the number of carious teeth, the number of teeth with deepened (4mm or more) periodontal pockets and self-perceived oral health.

Dental caries was visually and tactilely examined on five surfaces of every tooth. No radiographs were taken. Caries lesions were categorised into four different groups on the basis of restorative treatment need: 1) Crown caries was defined as a lesion in which dental caries reaches the dentin layer of the clinical crown; 2) Root caries appeared as softened surface of the root; 3) A combination of the first two; 4) Decayed root. Leaking fillings were defined as carious and remineralised lesions were classified as non-carious. If a tooth had any of the above mentioned lesions, it was marked as carious. 
Periodontal condition was assessed by probing periodontal pockets (WHO periodontal probe) on the mesiobuccal and distopalatal/distolingual surfaces of each tooth. The number of teeth with periodontal pockets $4 \mathrm{~mm}$ deep or deeper was used to measure the extent of periodontal infection. A total of three people were not probed due to insufficient co-operation or a lack of antibiotic prophylaxis.

Self-perceived oral health was assessed during the oral health interview with three questions: "Do you have pain/discomfort in your mouth at the moment? (Yes/No)", "Have you experienced pain or discomforts in the last twelve months? (Yes/No)", "How would you rate the condition of your mouth (Good/Quite Good/Average/Quite Poor/Poor)". In the analyses, the self-rated condition of mouth was categorised into two groups: Poor (Quite Poor/Poor) vs. Not poor (Good/Quite Good/Average).

\section{Explanatory variables}

The explanatory variables were Activities of Daily Living $(A D L)^{6}$, Instrumental Activities of Daily Living $(\mathrm{IADL})^{7}$, and the Functional Comorbidity Index $(\mathrm{FCl})^{8}$.

$A D L$ was assessed using Barthel Index $(B I)^{6}$ which is used to evaluate patient's independence in basic daily activities. The index includes ten domains: feeding, bathing, grooming, dressing, bowels (continent/incontinent), bladder (continent/incontinent), toilet use, transfer (bed to chair and back), mobility (on level surface), and stairs. Each domain is given points, with the maximum score being 100. In this study, ADL was classified as independent (BI score of 100), slight dependency for support (BI score between 99 and 91), and moderate dependency for support (BI score $\leq 90)$ according to Shah et al. ${ }^{23}$ Due to a small number of participants with severe $(\leq 60)$ and total dependency for support $(\leq$ 20), they were combined into the moderate dependency group. 
Lawton and Brody presented the Instrumental Activities of Daily Living scale in 1969 and proposed it as an aid to evaluating treatment plans and planning services among older people ${ }^{7}$. The IADL scale consists of eight instrumental, complex activities: ability to use the telephone, shopping, food preparation, housekeeping, doing the laundry, modes of travelling, being responsible for one's own medication and ability to handle finances. A person is given points of 0 or 1 in each category, and the total number gives the individual's IADL score, the maximum score being $8^{6}$. In this study, IADL was classified as no functional limitations (IADL score of 8), one limitation (IADL score of 7) and two or more limitations (IADL score $\leq 6$ ) according to the classification of León-Muñoz et al. ${ }^{24}$

Comorbidities were measured using the modified $\mathrm{FCl}$ (Functional Comorbidity Index) ${ }^{8}$. FCl was originally developed to analyse comorbidity with physical functioning as the outcome ${ }^{8}$. The modified FCl was formed by answering "yes" or "no" to 13 different diagnoses illustrated on the answer chart. Thirteen "yes" answers mean the highest number of comorbidities. The diagnoses are rheumatoid arthritis and other connective tissue disorders, osteoporosis, coronary artery diseases, heart failure, myocardial infarction, chronic asthma/chronic obstructive pulmonary disease (COPD), Parkinson's disease/multiple sclerosis, stroke, diabetes mellitus, depression, hearing impairment, visual impairment and obesity $(\mathrm{BMI}>30)^{8}$. The medical diagnoses were obtained by selfreporting, from medical reports or by a physician's assessment. In this study population, the $\mathrm{FCl}$ scores varied from 0 to 8 and the $\mathrm{FCl}$ score was categorised according to its distribution into three categories: $0-1,2-3$ and 4-8.

Other variables

The other variables were age, gender, education and variables related to oral health and cognition. The oral health variables were toothbrushing frequency (at least twice a day vs. 
more seldom), salivary secretion (non-stimulated salivary flow rate $<0.1 \mathrm{ml} / \mathrm{min} v s . \geq 0.1$ $\mathrm{ml} / \mathrm{ml}$; stimulated salivary flow rate $<1 \mathrm{ml} / \mathrm{min} v s$. $\geq 1 \mathrm{ml} / \mathrm{ml}$ ), dental office visiting pattern (when necessary or never vs. regularly), and dental plaque. The presence of dental plaque (yes/no, tooth level) was visually examined on the labial/buccal and palatal/lingual surfaces of all the teeth after they were dried with an air syringe. If any visible plaque was present, the tooth was marked as having dental plaque.

A study nurse assessed the cognitive function of each subject by using the Mini-Mental State Examination (MMSE) ${ }^{25}$, where the maximum score was 30 and scores $\leq 24$ were interpreted as impaired cognition.

\section{Statistical methods}

Prevalence rate ratios (PRRs) and their 95\% confidence intervals $(\mathrm{Cl})$ were estimated for the number of teeth with caries and deepened periodontal pockets (continuous variables) using Poisson regression model and for the self-perceived oral health variables (categorical variables) using Poisson regression model with robust error variance. Models were adjusted for age, gender, education and MMSE and all statistical analyses were conducted with SPSS 24.0 software for Windows.

\section{Results}

The mean age of the participants was 80.6 and 70 percent of them were women (Table 1). About forty percent of the participants had a low physical ability (at most moderate dependency for support or $\geq 2$ limitations in $I A D L)$ or had several comorbidities $(F C I \geq 4)$. Participants with lowest physical ability had more dental caries (moderate dependency for support or $\geq 2$ limitations in IADL), whereas deepened periodontal pockets ( $\geq 4 \mathrm{~mm}$ ) were not consistently distributed according to level of physical ability (Table 1). Self-perceived oral health was the lowest and more oral pain was reported by participants with the lowest 
physical ability (BI score $\leq 90$ or IADL score $\leq 6$ ) and by those with several comorbidities $(\mathrm{FCl} \geq 4)$. Additional descriptive information can be found from the Table 1, whereas Tables 2 and 3 show both crude and adjusted associations of explanatory variables (ADL, IADL, FCI) with oral health.

After adjustment for confounding factors, dependency for support in the activities of daily life (ADL) associated inversely with the number of teeth with deepened periodontal pockets, but not with the number of carious teeth, though, the associations were not statistically significant (Table 2). Slight dependency for support in the activities of daily life (ADL) associated inversely with poor self-perceived oral health and pain/discomfort in the mouth, whereas moderate dependency for support associated directly with them (Table 3). Most of the associations were inconsistent or not statistically significant.

Limitations in the instrumental activities of daily life (IADL) associated with both the number of carious teeth and the number of teeth with deepened periodontal pockets, although not at the p-value level 0.05 (Table 2). The number of limitations in the IADL associated also with poor self-perceived oral health and with pain/discomfort in the mouth with PRRs varying between 1.14 and 1.27 (continuous) (Table 3).

Comorbidity $(\mathrm{FCl})$ associated more strongly with the number of carious teeth than with the number of teeth with deepened periodontal pockets (Table 2). For the number of carious teeth, the PRRs varied from 1.52 (2-3 diagnoses) to 1.34 (4-8 diagnoses). For the number of teeth with deepened periodontal pockets, the associations were almost nonexisting. Out of subjective oral health variables, $\mathrm{FCl}$ associated most strongly with pain/discomfort in the mouth at the moment (PRR: 2.51, Cl: 1.35-4.66) (Table 3). 


\section{Discussion}

This study suggests that participants with poor physical ability or with comorbidities have a higher likelihood to have poor subjective oral health (poor self-perceived oral health and pain/discomfort in the mouth), whereas only participants with comorbidities had a somewhat higher likelihood to have poor objective oral health (dental caries). The results are partially parallel with previous studies where decreased physical ability was found to be associated with oral diseases ${ }^{9-12}$, and with studies where poor physical ability was associated with the pain and discomfort dimensions of OHRQoL ${ }^{15,16}$.

Interestingly, both decreased physical ability and comorbidities associated more strongly with poor self-perceived oral health and symptoms than with objective measures of oral health. It can be speculated that older people with multimorbidity and poor physical ability would be more likely to report poorer self-perceived oral health than their healthier counterparts. This assumption is supported by previous studies that found associations between poor physical health and decreased OHRQoL ${ }^{15-20}$. On the other hand, it is worth keeping in mind that the participants were relatively old (mean age 80.6 years) and this might affect participants' attitudes towards oral symptoms and reporting them.

There are several self-explanatory mechanisms that could explain why poor physical ability and comorbidities are related to oral diseases. These include declined oral self-care or irregular dental visits due to a poor physical ability; and a lowered salivary flow rate, due to high age, comorbidities, or medications. The above mentioned further highlight the importance of maintaining sufficient oral hygiene and regular dental visits despite a declined physical ability or comorbidities.

There are many aspects in this study that increase the validity of the study. The study population of the Oral Health GeMS study was homogeneous in terms of age and they 
also lived in a small region and belonged to the same ethnic group. We reduced confounding by excluding smokers and limiting the study population to home-dwelling dentate people. Despite these attempts to reduce confounding and adjusting for potential confounders, there may still be residual confounding related to socioeconomic factors, which have been found to be associated with oral health ${ }^{26}$, oral health behaviour ${ }^{27}$ and daily functioning ${ }^{28}$. One source of confounding could also be participants' attitudes towards oral health and general health.

The clinical outcome variables used in this study were measured in oral clinical examinations by two trained dentists. The oral clinical examination was standardised, and performed using a pre-written protocol, which increases the reliability of the examinations. On the other hand, the high age of the participants and the length of the examinations meant that no parallel or repeated examinations were carried out.

The clinical outcome variables themselves include also several limitations. Firstly, dental caries and periodontal pockets were measured only on the tooth-level, which may have caused bias toward zero, i.e., the true association may be stronger than observed. Secondly, the registration of dental caries was based only on the restorative treatment need and this differs from the commonly used methods such as DMFT and ICDAS ${ }^{29}$. Thirdly, the periodontal condition was registered only using probing depth (periodontal pockets $\geq 4 \mathrm{~mm}$ ), which might have underestimated the extent and severity of periodontal disease. Furthermore, this robust registration also differs from the commonly used epidemiological registration method (includes also attachment loss) ${ }^{30,31}$. All the abovementioned limitations should be taken into consideration, when interpreting or generalizing the results. 
The self-perceived oral health was assessed using only three questions, which is relatively narrow perspective of OHRQoL. This choice could be justified with the fact that the aim was on the oral symptoms and health rather than oral function, and for this purpose the three used questions can be thought adequate.

Regarding the validity of the explanatory variables, $\mathrm{ADL}^{6}$ and IADL ${ }^{7}$ have been previously validated and they have been found to be useful in evaluating changes in disability 32 . Regarding the validity of the $\mathrm{FCl}$, Groll et al. reported that the $\mathrm{FCl}$ was better or equal in classifying people having poor and good function when compared with other comorbidity indexes ${ }^{8}$, and the $\mathrm{FCl}$ has been reported to have good inter-rater reliability among trained research staff gathering data for the $\mathrm{FCl}^{33}$.

\section{Conclusion}

Older people with impaired physical ability and comorbidities are more likely to have oral discomfort and have poor self-perceived oral health. In addition, it appears that the measures for physical ability and comorbidities associate more with subjective oral health than with objective oral health.

\section{Acknowledgement}

The Geriatric Multidisciplinary Strategy for the Good Care of the Elderly study was financially supported by the Social Insurance Institute and the City of Kuopio 


\section{References}

1. Ageing in the Twenty-First Century-A Celebration and A Challenge. United Nations Population Fund (UNFPA), New York, and HelpAge International, London. 2012.

2. Brown LJ. Dental Services Among Elderly Americans: Utilization, Expenditures, and Their Determinants. In: Lamster IB, Northridge ME (eds). Improving Oral Health for the Elderly. Springer. New York: 2008. pp 436- 476.

3. Li KY, Wong MC, Lam KF, Schwarz E. Age, period, and cohort analysis of regular dental care behavior and edentulism: A marginal approach. BMC Oral Health 2011;

4. Suominen AL, Varsio S, Helminen S, Nordblad A, Lahti S, Knuuttila M. Dental and periodontal health in Finnish adults in 2000 and 2011. Acta Odontol Scand. 2018; 76(5): 305-13.

5. Herr M, Arvieu J-J, Aegerter P, Robine J-M, Ankri J. Unmet health care needs of older people: prevalence and predictors in a French cross-sectional survey. The Eur J Pub. Health 2014; 24: 808-13.

6. Mahoney FI, Barthel DW. Functional evaluation: the Barthel Index. Md State Med J. 1965; 14: 61-65.

7. Lawton MP, Brody EM. Assessment of older people: self-maintaining and instrumental activities of daily living. Gerontologist. 1969; 9: 179-86.

8. Groll DA, To T, Bombardier C, Wright JG. The development of a comorbidity index with physical function as the outcome. J Clin Epidemiol. 2005; 58: 595-602.

9. Avlund K., Holm-Pedersen P, Schroll M. Functional Ability and Oral Health Among Older People: A Longitudinal Study from Age 75 to 80. JAGS. 2001; 49: 954-62. 
10. Avlund K, Holm-Pedersen P, Morse D E, Viitanen M, Winblad B. Tooth loss and caries prevalence in very old Swedish people: the relationship to cognitive function and functional ability. Gerodontology. 2004; 21: 17-26.

11. Holmén A., Strömberg E., Hagman-Gustafsson M-L, Wårdh I, Gabre P. Oral status in home-dwelling elderly dependent on moderate or substantial supportive care for daily living: prevalence of edentulous subjects, caries and periodontal disease. Gerodontology. 2012; 29: 503-11.

12. Saintrain MVL, Saintrain SV, Sampaio EGM, et al. Older adults' dependence in activities of daily living: Implications for oral health. Public Health Nurs. 2018; 35(6): 473-81.

13. Koistinen S, Olai L, Ståhlnacke K, Fält A, Ehrenberg A. Oral health and oral care in short-term care: prevalence, related factors and coherence between older peoples' and professionals' assessments. Scand J Caring Sci. 2019; 33(3): 712-22.

14. Tuuliainen E, Autonen-Honko Nen K, Nihtilä A, et al. Oral Health and Hygiene and Association of Functional Ability: A Cross-Sectional Study Among Old Home Care Clients. Oral Health Prev Dent. 2020; 18(2): 253-62.

15. Ikebe K, Watkins CA, Ettinger RL, Sajima H, Nokubi T. Application of short-form oral health impact profile on elderly Japanese. Gerodontology. 2004; 21(3): 167-76.

16. Jensen PM, Saunders RL, Thierer T, Friedman B. Factors associated with oral healthrelated quality of life in community-dwelling elderly persons with disabilities. J Am Geriatr Soc. 2008; 56(4): 711-17. 
17. Miura H, Yamasaki K, Morizaki N, Moriya S, Sumi Y. Factors influencing oral healthrelated quality of life (OHRQoL) among the frail elderly residing in the community with their family. Arch Gerontol Geriatr. 2010; 51(3) :e62-65.

18. Castrejon-Perez RC, Borges-Yanez SA, Irigoyen-Camacho ME, Cruz-Hervert LP. Negative impact of oral health conditions on oral health related quality of life of community dwelling elders in Mexico City, a population-based study. Geriatr Gerontol Int. 2017; 17(5): 744-52.

19. Koistinen S, Olai L, Ståhlnacke K, Fält A, Ehrenberg A. Oral health-related quality of life and associated factors among older people in short-term care. Int J Dent Hyg. 2019; 18(2): 163-72.

20. Hatipoglu MG, Kabay SC, Güven G. The clinical evaluation of the oral status in Alzheimer-type dementia patients. Gerodontology. 2011; 28: 302-6.

21. Tikkanen P, Lönnroos E, Sipilä S, Nykänen I, Sulkava R, Hartikainen S. Effects of comprehensive geriatric assessment-based individually targeted interventions on mobility of pre-frail and frail community-dwelling older people. Geriatr Gerontol Int. 2015; 15: 80-88.

22. Komulainen K, Ylöstalo P, Syrjälä AM, Ruoppi P, Knuuttila M, Sulkava R, Hartikainen S. Determinants for preventive oral health care need among community-dwelling older people: a population-based study. Spec Care Dentist. 2014; 34(1): 19-26.

23. Shah S, Vanclay F, Cooper B. Improving the sensitivity of the Barthel Index for stroke rehabilitation. J Clin Epidemiol 1989; 42:703-09. 
24. León-Muñoz LM, López-García E, Graciani A, Guallar-Castillón P, Banegas JR, Rodríguez-Artalejo F. Functional status and use of health care services: Longitudinal study on the older adult population in Spain. Maturitas. 2007; 58: 377-86.

25. Folstein M, Folstein S, McHugh P. Mini-Mental State: a practical method for grading the cognitive state of patients for the clinician. J Psych Res. 1975; 12: 189-98.

26. Schwendicke F, Dörfer CE, Schlattmann P, Foster Page L, Thomson WM, Paris S. Socioeconomic inequality and caries: a systematic review and meta-analysis. $J$ Dent Res. 2015; 94: 10-18.

27. Harris RV, Pennington A, Whitehead M. Preventive dental visiting: a critical interpretive synthesis of theory explaining how inequalities arise. Community Dent Oral Epidemiol. 2016 Dec 6. doi: 10.1111/cdoe.12268.

28. d'Orsi E, Xavier AJ, Steptoe A, et al. Socioeconomic and lifestyle factors related to instrumental activity of daily living dynamics: results from the English Longitudinal Study of Ageing. Am Geriatr Soc. 2014; 62: 1630-39.

29. World Health Organization. Oral Health Survey: basic methods. Geneva: 2013. http://www.who.int/oral_health/publications/9789241548649/en

30. American Academy of Periodontology. American Academy of Periodontology Task Force Report on the Update to the 1999 classification of periodontal diseases and conditions. J Periodontol 2015; 86: 835-38.

31.Kassebaum N, Bernabé E, Dahiya M, Bhandari B, Murray C, Marcenes W. Global burden of severe periodontitis in 1990-2010: a systematic review and metaregression. J Dent Res 2014; 93: 1045-53. 
32. Finlayson M, Mallinson T, Barbosa VM. Activities of daily living (ADL) and instrumental activities of daily living (IADL) items were stable over time in a longitudinal study on aging. J Clin Epidemiol. 2005; 58: 338-349.

33. Fan E, Gifford JM, Chandolu S, Colantuoni E, Pronovost PJ, Needham DM. The functional comorbidity index had high inter-rater reliability in patients with acute lung injury. BMC Anesthesiol. 2012 13; 12: 21. 
Table 1. Characteristics of the study population by physical ability measured by the independency in $\mathrm{ADL}$, the number of limitations in IADL, and comorbidity measured by the number diagnoses in the $\mathrm{FCl}$

\begin{tabular}{|c|c|c|c|c|c|c|c|c|c|}
\hline \multirow[t]{5}{*}{ Variable } & \multirow{2}{*}{\multicolumn{3}{|c|}{ Physical ability, ADL }} & \multirow{2}{*}{\multicolumn{3}{|c|}{$\begin{array}{c}\text { Physical ability, } \\
\text { IADL }\end{array}$}} & \multirow{2}{*}{\multicolumn{3}{|c|}{ Comorbidity, $\mathrm{FCl}$}} \\
\hline & & & & & & & & & \\
\hline & \multicolumn{3}{|c|}{ Level of independency } & \multicolumn{3}{|c|}{$\begin{array}{l}\text { Number of } \\
\text { limitations }\end{array}$} & \multicolumn{3}{|c|}{$\begin{array}{l}\text { Number of } \\
\text { diagnoses }\end{array}$} \\
\hline & \multirow{2}{*}{$\begin{array}{l}\text { Independ } \\
\text { ent }\end{array}$} & \multirow{2}{*}{$\begin{array}{l}\text { Slight } \\
\text { depende } \\
\text { ncy for } \\
\text { support }\end{array}$} & \multirow{2}{*}{$\begin{array}{l}\text { At least } \\
\text { moderat } \\
\text { e } \\
\text { depende } \\
\text { ncy for } \\
\text { support }\end{array}$} & \multirow[t]{2}{*}{0} & \multirow[t]{2}{*}{1} & \multirow{2}{*}{$\begin{array}{l}\geq \\
2\end{array}$} & \multirow[t]{2}{*}{$0-1$} & \multirow[t]{2}{*}{$2-3$} & \multirow[t]{2}{*}{$4-8$} \\
\hline & & & & & & & & & \\
\hline $\mathrm{n}$ & 117 & 22 & 20 & 87 & 3 & 3 & 58 & 66 & 37 \\
\hline
\end{tabular}

Sociodemogr

aphic

variables

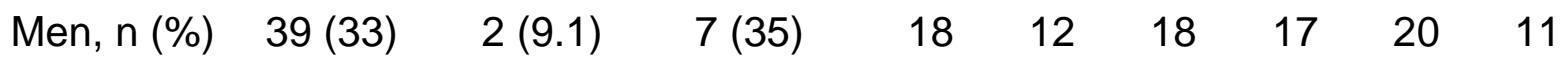

$\begin{array}{lllll}(21) & (34) & (47) & (30) & (30)\end{array}$

$\begin{array}{llllllllll}\text { Age, mean } & 80.2 & 80.4 & 82.2 & 80.0 & 80.5 & 82.0 & 79.9 & 80.9 & 81.2\end{array}$

$\begin{array}{lllllllll} \pm(\mathrm{SD}) & (3.61) & (2.75) & (3.72)\end{array} \quad\left(\begin{array}{llllll}3.4 & (2.8 & (4.3 & (3.1 & (4.0 & (3.5\end{array}\right.$

$\begin{array}{lllll}4) & 4) & \text { 6) }\end{array}$

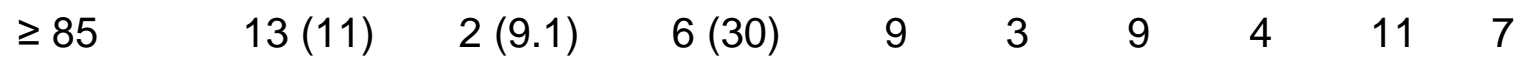

$\begin{array}{lllllll}\text { years, } \mathrm{n} & \text { (10) } & (8.6 & (24) & (6.9 & (17) & \text { (19) }\end{array}$

$(\%)$

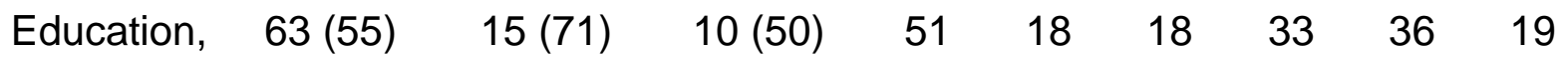

$\geq 7$ years,

$\begin{array}{llllll}(61) & (51) \quad(47) \quad(57) \quad(55) \quad(54)\end{array}$

$n(\%)^{\ddagger}$ 


\section{Dental}

variables

$\begin{array}{lccccccccc}\text { Number of } & 14.6 & 16.8 & 13.0 & 15.6 & 15.4 & 12.3 & 14.9 & 14.1 & 15.3 \\ \text { teeth, } & (8.11) & (8.51) & (7.95) & (7.8 & (8.8 & (7.7 & (8.2 & (8.4 & (7.5 \\ \text { mean } \pm & & & & 5) & 0) & 2) & 7) & 3) & 1)\end{array}$

(SD)

$\begin{array}{llllllllll}\text { Number of } & 2.67(4.0) & 3.35 & 2.21 & 2.64 & 3.00 & 2.49 & 2.69 & 2.59 & 2.76\end{array}$

$\begin{array}{lllllllll}\text { teeth with } & (3.23) & (2.78) & (3.6 & (4.9 & (2.7 & (3.4 & (3.2 & (4.9\end{array}$

$\begin{array}{lllllll}\text { periodontal } & \text { 0) } & \text { 4) } & \text { 3) } & \text { 9) } & \text { 9) } & \text { 0) }\end{array}$

pockets $\geq 4$

$\mathrm{mm}$, mean

$\pm(\mathrm{SD})$

$\begin{array}{llllllllll}\text { Number of } & 1.16 & 1.20 & 1.63 & 1.05 & 1.00 & 1.71 & 0.83 & 1.44 & 1.30\end{array}$

$\left.\begin{array}{lllllllllll}\text { carious } & (1.78) & (1.94) & (3.64)\end{array}\right)\left(\begin{array}{llllll}1.6 & (1.7 & (3.0 & (1.7 & (2.3 & (2.0\end{array}\right.$

teeth,

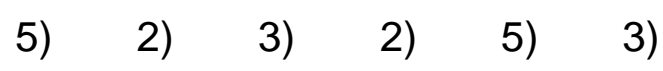

mean \pm

$(\mathrm{SD})$

$\begin{array}{llllllllll}\text { Number of } & 7.50 & 6.75 & 9.63 & 6.98 & 8.09 & 9.08 & 7.57 & 6.83 & 9.41\end{array}$

$\begin{array}{llllllllll}\text { teeth with } & (6.92) & (6.66) & (7.68) & (6.8 & (7.8 & (6.8 & (7.1 & (7.0 & (7.0\end{array}$

dental

6) 0$)$ 6) 0$)$ 0) 6)

plaque,

mean \pm

(SD)

Salivary

secretion 


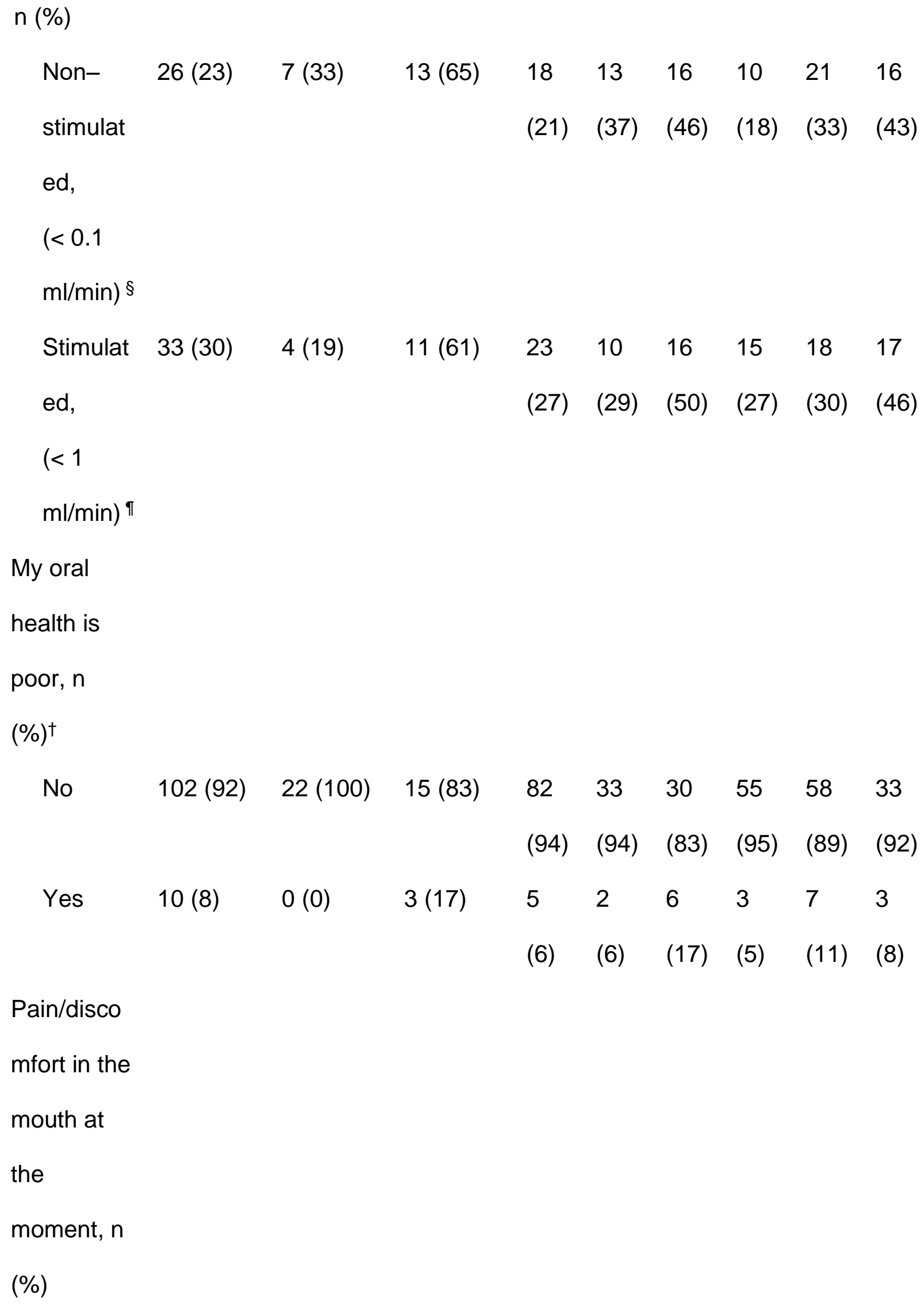

(6) (6) (17) (5) (11) (8)

Pain/disco

mfort in the

mouth at

the

moment, $\mathrm{n}$

$(\%)$ 
$\begin{array}{llllllllll}\text { No } & 83(71) & 19(86) & 11(55) & 62 & 23 & 18 & 47 & 46 & 21\end{array}$

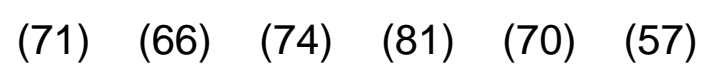

$\begin{array}{llllllllll}\text { Yes } & 34(29) & 3(14) & 9(45) & 25 & 12 & 10 & 11 & 20 & 16\end{array}$

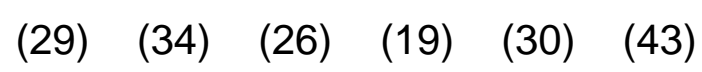

Pain/disco

mfort in the

mouth in

the past

twelve

months, $\mathrm{n}$

$(\%)^{\dagger}$

$\begin{array}{llllllllll}\text { No } & 79(68) & 18(82) & 8(44) & 62 & 26 & 19 & 40 & 46 & 21\end{array}$

$\begin{array}{llllll}(71) & (74) \quad(53) & (69) & (71) & (58)\end{array}$

$\begin{array}{llllllllll}\text { Yes } & 38(32) & 4(18) & 10(56) & 25 & 9 & 17 & 18 & 19 & 15\end{array}$

$\begin{array}{llllll}(29) & (26) \quad(47) \quad(31) & (29) \quad(42)\end{array}$

Dental

visits, $\mathrm{n}$

$(\%)^{\dagger}$

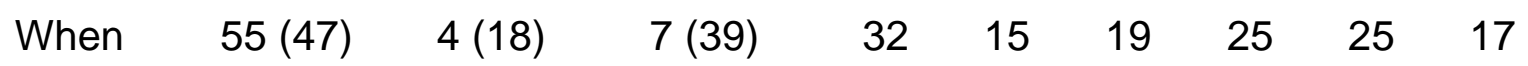

necessa

$\begin{array}{llllll}(37) & (43) & (53) & (43) & (39) & (47)\end{array}$

ry or

never

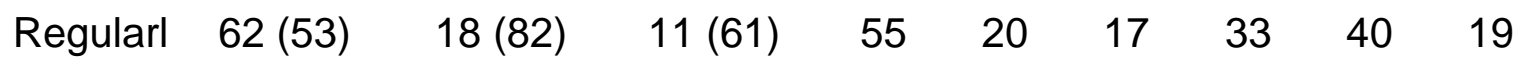

y

$\begin{array}{llllll}(63) & (57) \quad(47) & (57) \quad(62) & (53)\end{array}$ 
Toothbrush

ing, $\mathrm{n}(\%)^{\dagger}$

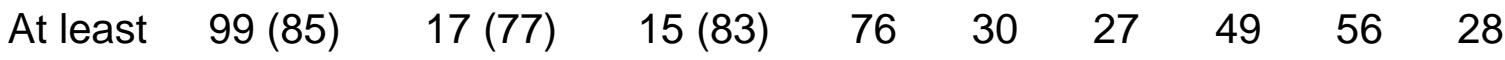

twice a

(87) $\quad(86 \quad(75) \quad(85) \quad(86) \quad(78)$

day

$\begin{array}{llllllllll}\text { more } & 18(15) & 5(23) & 3(7.0) & 11 & 5 & 9 & 9 & 9 & 8\end{array}$

seldom

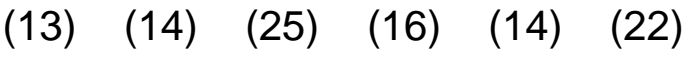

General

health-related

variables

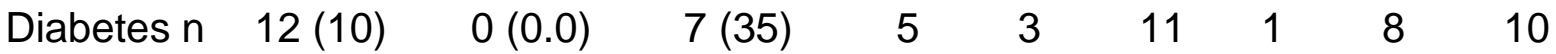

$(\%)^{\ddagger}$

$\begin{array}{llllll}5.7 & (8.6 & (29) & (1.7 & (12) & (27)\end{array}$

$\begin{array}{llllllllll}\text { MMSE } & 27.4 & 25.4 & 26.1 & 28.3 & 27.0 & 23.9 & 27.5 & 26.8 & 26.7\end{array}$

mean $\pm \quad(3.68) \quad(4.36) \quad(4.49) \quad\left(2.0 \quad\left(\begin{array}{llllll}2.6 & (5.8 & (2.9 & (4.7 & (3.4\end{array}\right.\right.$

(SD)

$\begin{array}{lllll}\text { 7) } & \text { 7) } & \text { 2) } & \text { 7) } & \text { 3) 2) }\end{array}$

$\begin{array}{llllllllll}\text { Number of } & 5.13 & 7.40 & 8.63 & 5.83 & 6.79 & 7.58 & 4.21 & 6.51 & 9.89\end{array}$

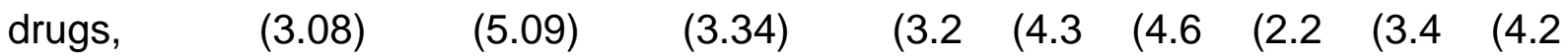

$\begin{array}{lllllll}\text { mean } \pm & 6) & \text { 5) } & \text { 4) } & \text { 7) } & \text { 1) } & \text { 7) }\end{array}$

(SD)

$† 2$ people missing, $₹ 3$ people missing, \& 5 people missing, § 8 people missing $A D L=$ Activities in Daily Living, $I A D L=$ Instrumental Activities in Daily Living, $\mathrm{FCl}=$ Functional Comorbidity Index, MMSE = Mini-Mental State Examination, MNA = Mini Nutritional Assessment 
Table 2. Crude and adjusted Poisson's multivariate regression models relating variables to the number of carious teeth and number of teeth with periodontal pockets.

\begin{tabular}{lll}
\hline Variable & Number of carious teeth & $\begin{array}{l}\text { Number of teeth with } \\
\text { periodontal pockets }\end{array}$ \\
& PRR $(95 \% \mathrm{Cl})$ & PRR $(95 \% \mathrm{Cl})$
\end{tabular}

\section{CRUDE MODELS}

ADL, level of independency
Independent
1.0
1.0
Slight dependency for
$0.79(0.51-1.22)$
$1.09(0.84-1.42)$
support
At least moderate
$1.46(0.99-2.16)$
$0.93(0.68-1.29)$
dependency for support
ADL Index, continuous
$1.01(0.98-1.03)$
$1.01(1.00-1.03)$

IADL, number of limitations

None

1.0

1.0

One

$0.97(0.66-1.43)$

$1.14(0.90-1.44)$

Two or more

$2.08(1.51-2.86)^{*}$

$1.21(0.95-1.54)$

Number of limitations, continuous

$1.27(1.17-1.38)$

$1.02(0.95-1.09)$

$\mathrm{FCl}$, number of diagnoses
0-1
1.0
1.0
2-3
$1.84(1.30-2.61)^{*}$
$1.02(0.82-1.27)$
4-8
$1.53(1.03-2.28)^{*}$
$1.04(0.81-1.35)$
Number of diagnoses,
$1.07(0.99-1.16)$
$0.97(0.92-1.03)$
continuous
Age (continuous)
$1.05(1.02-1.09)^{*}$
$1.02(0.99-1.04)$
Female

Gender 
Male

$0.90(0.66-1.23)$

$0.86(0.70-1.05)$

Education

$\begin{array}{lll}\geq 7 \text { years } & 1.0 & 1.0 \\ 0-6 \text { years } & 1.15(0.86-1.55) & 0.86(0.70-1.06) \\ \text { MMSE (continuous) } & 0.91(0.89-0.93)^{*} & 0.98(0.95-1.00)^{*} \\ \text { Saliva secretion } & & \\ \text { Non-stimulated } & 1.0 & 1.0 \\ \text { Normal } & 1.23(0.90-1.67) & 0.92(0.73-1.14) \\ \text { Reduced } & & \\ (<0.1 \mathrm{ml} / \mathrm{min}) & \end{array}$

Stimulated

Normal

1.0

1.0

Reduced

$1.52(1.13-2.06)^{*}$

$1.09(0.88-1.35)$

$(<1 \mathrm{ml} / \mathrm{min})$

Dental visits

Regularly

1.0

1.0

When necessary or never

$2.59(1.94-3.45)^{*}$

$1.67(1.38-2.03)^{*}$

Toothbrushing

At least twice a day

1.0

1.0

More seldom

$1.84(1.31-2.57)^{*}$

$0.70(0.51-0.95)^{*}$

\section{ADJUSTED MODELS ${ }^{\dagger}$}

ADL, level of independency

Independent

1.0

1.0

Slight dependency for

$0.67(0.43-1.05)$

$0.97(0.74-1.28)$ 


\begin{tabular}{lll}
\hline $\begin{array}{l}\text { At least moderate } \\
\text { dependency for support }\end{array}$ & $1.05(0.70-1.58)$ & $0.84(0.60-1.18)$ \\
ADL Index, continuous & $1.02(1.00-1.05)$ & $1.02(1.00-1.04)^{*}$ \\
IADL, number of limitations & & \\
None & 1.0 & 1.0 \\
One & $0.84(0.56-1.25)$ & $1.17(0.92-1.49)$ \\
Two or more & $1.18(0.77-1.81)$ & $1.20(0.88-1.63)$ \\
$\begin{array}{l}\text { Number of limitations, } \\
\text { continuous }\end{array}$ & $1.08(0.95-1.22)$ & $0.99(0.90-1.08)$ \\
FCI, number of diagnoses & & \\
$0-1$ & 1.0 & 1.0 \\
$2-3$ & $1.52(1.07-2.18)^{*}$ & $0.96(0.77-1.20)$ \\
$4-8$ & $1.34(0.89-2.01)$ & $1.00(0.77-1.30)$ \\
$\begin{array}{l}\text { Number of diagnoses, } \\
\text { continuous }\end{array}$ & $1.02(0.94-1.11)$ & $0.95(0.89-1.01)$ \\
\hline
\end{tabular}

PRR: prevalence rate ratio, Cl: confidence interval

ADL: Activities of Daily Living, IADL: Instrumental Activities of Daily Living, FCl: Functional Comorbidity Index, MMSE: Mini-Mental State Examination.

Data presented as risk ratios with $95 \%$ confidence interval.

${ }^{*} \mathrm{p}<0.05$

+ Adjusted for age, gender, education and cognition (MMSE). 
Table 3. Crude and adjusted Poisson's multivariate regression models relating variables to the self-perceived oral health and pain/discomfort in the mouth

$\begin{array}{llll}\text { Variable } & \begin{array}{l}\text { My oral health is } \\ \text { poor }\end{array} & \begin{array}{l}\text { Pain/discomfort in } \\ \text { the mouth at the } \\ \text { moment }\end{array} & \begin{array}{l}\text { Pain/discomfort in } \\ \text { the mouth in the } \\ \text { past twelve months }\end{array} \\ \text { PRR }(95 \% \mathrm{Cl}) & \text { PRR }(95 \% \mathrm{Cl}) & \text { PRR }(95 \% \mathrm{Cl})\end{array}$

\section{CRUDE MODELS}

$A D L$, level of

independency

Independent

1.0

1.0

1.0

Slight

dependency for

support

At least

moderate

$1.95(0.59-6.42)$

$0.47(0.16-1.39)$

$0.56(0.22-1.41)$

dependency for

support

ADL Index, continuous

$1.00(0.96-1.04)$

$1.00(0.97-1.02)$

$0.99(0.97-1.01)$

$1.71(1.05-2.79)^{*}$

$1.55(0.88-2.71)$

$1.71(1.05-2.79)$

IADL, number of limitations

None

1.0

1.0

1.0

One

$0.99(0.20-4.89)$

$1.19(0.68-2.10)$

$0.90(0.47-1.72)$

Two or more

$2.90(0.95-8.90)$

$0.92(0.49-1.71)$

$1.64(1.02-2.65)^{*}$

Number of

$1.38(1.11-1.73)^{*}$

$1.03(0.89-1.20)$

$1.16(1.05-1.28)^{*}$

limitations,

continuous

$\mathrm{FCl}$, number of diagnoses
0-1
1.0
1.0
1.0
2-3
$2.08(0.56-7.68)$
$1.60(0.84-3.05)$
$0.94(0.55-1.61)$
4-8
$1.61(0.34-7.56)$
$2.28(1.19-4.36)^{*}$
$1.34(0.78-2.31)$ 


\begin{tabular}{|c|c|c|c|}
\hline $\begin{array}{l}\text { Number of } \\
\text { diagnoses, } \\
\text { continuous }\end{array}$ & $1.08(0.81-1.43)$ & $1.15(1.01-1.30)^{*}$ & $1.08(0.95-1.23)$ \\
\hline Age (continuous) & $1.07(0.96-1.20)$ & $1.01(0.95-1.08)$ & $1.00(0.95-1.07)$ \\
\hline \multicolumn{4}{|l|}{ Gender } \\
\hline Female & 1.0 & 1.0 & 1.0 \\
\hline Male & $1.49(0.51-4.32)$ & $0.64(0.35-1.17)$ & $1.61(1.04-2.50)^{*}$ \\
\hline \multicolumn{4}{|l|}{ Education } \\
\hline$\geq 7$ years & 1.0 & 1.0 & 1.0 \\
\hline $0-6$ years & $1.51(0.53-4.29)$ & $1.44(0.87-2.36)$ & $0.95(0.61-1.49)$ \\
\hline MMSE (continuous) & $0.92(0.88-0.97)^{\star}$ & $1.07(0.99-1.15)$ & $1.01(0.96-1.07)$ \\
\hline \multicolumn{4}{|l|}{ Saliva secretion } \\
\hline \multicolumn{4}{|l|}{ Non-stimulated } \\
\hline Normal & 1.0 & 1.0 & 1.0 \\
\hline $\begin{array}{l}\text { Reduced } \\
(<0.1 \mathrm{ml} / \mathrm{min})\end{array}$ & $1.38(0.43-4.50)$ & $1.49(0.92-2.42)$ & $0.94(0.56-1.57)$ \\
\hline \multicolumn{4}{|l|}{ Stimulated } \\
\hline Normal & 1.0 & 1.0 & 1.0 \\
\hline $\begin{array}{l}\text { Reduced } \\
(<1 \mathrm{ml} / \mathrm{min})\end{array}$ & $1.05(0.27-4.03)$ & $1.65(1.02-2.67)^{\star}$ & $0.84(0.50-1.41)$ \\
\hline \multicolumn{4}{|l|}{ Dental visits } \\
\hline Regularly & 1.0 & 1.0 & 1.0 \\
\hline $\begin{array}{l}\text { When necessary } \\
\text { or never }\end{array}$ & $3.09(0.99-9.61)$ & $1.21(0.75-1.95)$ & $1.48(0.95-2.31)$ \\
\hline \multicolumn{4}{|l|}{ Toothbrushing } \\
\hline $\begin{array}{l}\text { At least twice a } \\
\text { day }\end{array}$ & 1.0 & 1.0 & 1.0 \\
\hline More seldom & $2.27(0.76-6.83)$ & $0.48(0.19-1.21)$ & $1.37(0.82-2.30)$ \\
\hline
\end{tabular}




\begin{tabular}{|c|c|c|c|}
\hline \multicolumn{4}{|l|}{$\begin{array}{l}\frac{A D J U S T E D}{M O D E L S^{\dagger}} \\
\frac{A D L, \text { level of }}{\text { independency }}\end{array}$} \\
\hline Independent & 1.0 & 1.0 & 1.0 \\
\hline $\begin{array}{l}\text { Slight dependency } \\
\text { for support }\end{array}$ & - & $0.37(0.10-1.38)$ & $0.66(0.26-1.68)$ \\
\hline $\begin{array}{l}\text { At least moderate } \\
\text { dependency for } \\
\text { support }\end{array}$ & $1.53(0.47-4.94)$ & $1.70(0.93-3.08)$ & $1.74(1.00-3.03)^{*}$ \\
\hline $\begin{array}{l}\text { ADL Index, } \\
\text { continuous } \\
\text { IADL }\end{array}$ & $1.00(0.96-1.05)$ & $1.00(0.97-1.02)$ & $0.99(0.97-1.01)$ \\
\hline \multicolumn{4}{|l|}{$\begin{array}{l}\text { IADL, number of } \\
\text { limitations }\end{array}$} \\
\hline None & 1.0 & 1.0 & 1.0 \\
\hline One & $0.80(0.15-4.43)$ & $1.52(0.86-2.69)$ & $0.87(0.46-1.52)$ \\
\hline Two or more & $1.60(0.50-5.13)$ & $1.58(0.82-3.06)$ & $1.74(0.99-3.04)$ \\
\hline $\begin{array}{l}\text { Number of } \\
\text { limitations, } \\
\text { continuous }\end{array}$ & $1.27(1.03-1.57)^{\star}$ & $1.14(1.01-1.28)^{*}$ & $1.20(1.06-1.35)^{\star}$ \\
\hline \multicolumn{4}{|l|}{$\begin{array}{l}\mathrm{FCl} \text {, number of } \\
\text { diagnoses }\end{array}$} \\
\hline $0-1$ & 1.0 & 1.0 & 1.0 \\
\hline $2-3$ & $1.70(0.46-6.24)$ & $1.63(0.85-3.11)$ & $0.96(0.56-1.64)$ \\
\hline $4-8$ & $1.43(0.32-6.38)$ & $2.51(1.35-4.66)^{\star}$ & $1.41(0.82-2.42)$ \\
\hline $\begin{array}{l}\text { Number of } \\
\text { diagnoses, }\end{array}$ & $1.04(0.80-1.36)$ & $1.20(1.05-1.36)^{*}$ & $1.10(0.96-1.26)$ \\
\hline
\end{tabular}

PRR: prevalence rate ratio, $\mathrm{Cl}$ : confidence interval

ADL: Activities of Daily Living, IADL: Instrumental Activities of Daily Living, FCl: Functional Comorbidity Index, MMSE: Mini-Mental State Examination.

Data presented as risk ratios with $95 \%$ confidence interval.

${ }^{*} p<0.05$

† Adjusted for age, gender, education and cognition (MMSE). 